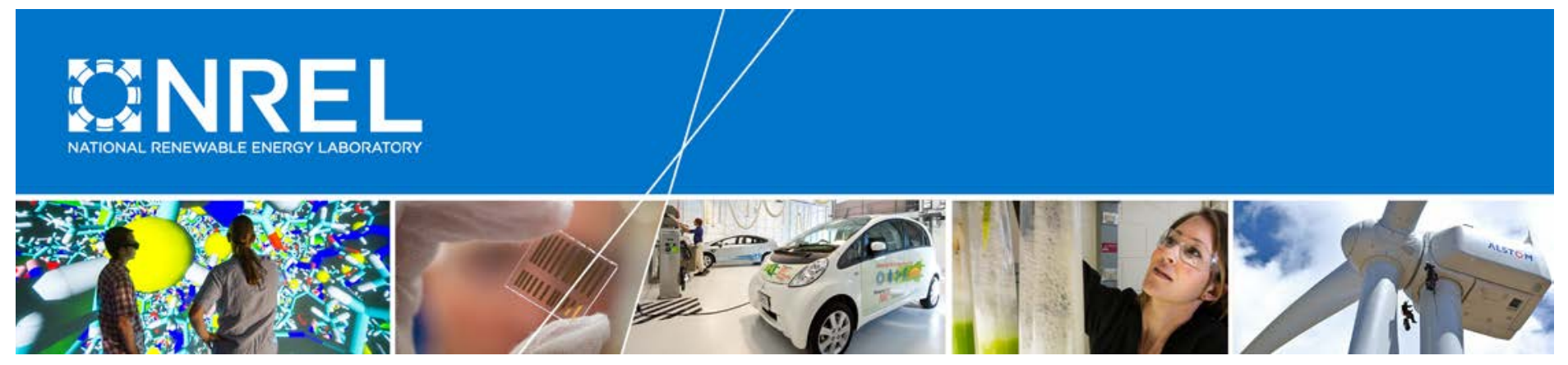

\title{
Improving Power System Modeling: A Tool to Link Capacity Expansion and Production Cost Models
}

Victor Diakov, Wesley Cole, Patrick Sullivan, Gregory Brinkman, and Robert Margolis National Renewable Energy Laboratory

NREL is a national laboratory of the U.S. Department of Energy Office of Energy Efficiency \& Renewable Energy Operated by the Alliance for Sustainable Energy, LLC

This report is available at no cost from the National Renewable Energy Laboratory (NREL) at www.nrel.gov/publications.

Technical Report

NREL/TP-6A20-64905

November 2015 


\section{Improving Power System Modeling: A Tool to Link Capacity Expansion and Production Cost Models}

Victor Diakov, Wesley Cole, Patrick Sullivan, Gregory Brinkman, and Robert Margolis National Renewable Energy Laboratory

Prepared under Task No. SS13.1020

NREL is a national laboratory of the U.S. Department of Energy Office of Energy Efficiency \& Renewable Energy Operated by the Alliance for Sustainable Energy, LLC

This report is available at no cost from the National Renewable Energy Laboratory (NREL) at www.nrel.gov/publications.

National Renewable Energy Laboratory 15013 Denver West Parkway Golden, CO 80401

303-275-3000 • www.nrel.gov

\section{Technical Report}

NREL/TP-6A20-64905

November 2015

Contract No. DE-AC36-08G028308 


\title{
NOTICE
}

This report was prepared as an account of work sponsored by an agency of the United States government. Neither the United States government nor any agency thereof, nor any of their employees, makes any warranty, express or implied, or assumes any legal liability or responsibility for the accuracy, completeness, or usefulness of any information, apparatus, product, or process disclosed, or represents that its use would not infringe privately owned rights. Reference herein to any specific commercial product, process, or service by trade name, trademark, manufacturer, or otherwise does not necessarily constitute or imply its endorsement, recommendation, or favoring by the United States government or any agency thereof. The views and opinions of authors expressed herein do not necessarily state or reflect those of the United States government or any agency thereof.

This report is available at no cost from the National Renewable Energy Laboratory (NREL) at www.nrel.gov/publications.

Available electronically at SciTech Connect http:/www.osti.gov/scitech

Available for a processing fee to U.S. Department of Energy and its contractors, in paper, from:

\author{
U.S. Department of Energy \\ Office of Scientific and Technical Information \\ P.O. Box 62 \\ Oak Ridge, TN 37831-0062 \\ OSTI http://www.osti.gov \\ Phone: 865.576.8401 \\ Fax: 865.576.5728 \\ Email: reports@osti.gov
}

Available for sale to the public, in paper, from:

\author{
U.S. Department of Commerce \\ National Technical Information Service \\ 5301 Shawnee Road \\ Alexandria, VA 22312 \\ NTIS http://www.ntis.gov \\ Phone: 800.553 .6847 or 703.605 .6000 \\ Fax: 703.605.6900 \\ Email: orders@ntis.gov
}




\section{Acknowledgments}

This work was funded by the Solar Energy Technologies Office of the Department of Energy Office of Energy Efficiency and Renewable Energy under contract number DE-AC3608GO28308. The authors thank Jennie Jorgenson and Eduardo Ibanez for their help supporting PLEXOS operability and analyzing transmission expansion results, Ben Sigrin and Michael Gleason for help in the initial stages of building the geographic representation of the results, and Billy Roberts for producing the maps included in this report. The authors also thank Trieu Mai and Nate Blair for providing helpful comments and suggestions. 


\section{Nomenclature or List of Acronyms}

$\mathrm{CC}$

CT

CEM

ERCOT

GAMS

LP

MIP

NREL

OOO

PCM

PLEXOS

ReEDS

TEPPC

WECC

WWSIS

WWSIS-2 combined cycle (gas generator)

combustion turbine

capacity expansion model

Electric Reliability Council of Texas

general algebraic modeling system

linear programming

mixed-integer programming

National Renewable Energy Laboratory

onset of ontologies via optimization

Production cost model

PLEXOS Integrated Energy Model

Renewable Energy Deployment System

Transmission Expansion Planning Policy Committee

Western Electricity Coordination Council

Western Wind and Solar Integration Study

Western Wind and Solar Integration Study Phase 2 


\section{Executive Summary}

Capacity expansion models (CEMs) provide a high-level long-term view of the evolving power system. Because of computational limits, CEMs generally cannot model detailed system dispatch and instead employ reduced-form dispatch models. It is important, however, that these long-term models maintain the viability of power system operation in the short-term (daily, hourly and subhourly) scales. Production-cost models (PCMs) simulate routine power system operations on these shorter time scales using detailed load, transmission, and generation fleet data by minimizing production costs and following reliability requirements. When based on CEM outputs of future generating unit retirements and buildup, PCMs provide more detailed simulations for the short-term system operation and, consequently can confirm the validity of capacity expansion outputs. For PCM simulations based on a CEM solution, the generator mix is the result of a logical sequence of unit retirement and buildup resulting from policy and economic incentives; in this sense, the CEM solution is "evolutionarily sound." This provides the PCM with a systematic approach for translating high-level projections into a detailed grid description that is generally more reliable and less time intensive than implementing the translation by hand. For these reasons, we bridge a capacity expansion model with a production cost model by building a capacity-expansion-to-production-cost-model bridge we call the Linking Tool.

The Linking Tool is built to impose capacity expansion model outputs onto production cost model inputs. NREL's Renewable Energy Deployment System (ReEDS) model and Energy Exemplar's PLEXOS tool are the capacity expansion and the production cost models, respectively, that are used in this work. Via the Linking Tool, PLEXOS provides finer details of operation for the regionally-defined ReEDS outputs. Although the Linking Tool is currently designed for the combined use of ReEDS and PLEXOS, it can be expanded to include other capacity expansion models (e.g., the Resource Planning Model).

One of the most important differences between the ReEDS and PLEXOS descriptions of the electric power system is the level of detail. ReEDS operates at regional level (35 ReEDS regions cover the Western Interconnect), while PLEXOS can operate at bus level (with over 17,000 buses in the database for the Western Interconnect); also, ReEDS uses 17 time slices to simulate annual system dispatch with generalized representations of ancillary service requirements, whereas PLEXOS provides full-year, hourly or sub-hourly (down to one-minute) simulation of the electric system operation, including ancillary service specifications, forecast errors, and unit commitment. Thus, the Linking Tool provides a framework for automating the creation of a PLEXOS set of inputs based on the outputs of a ReEDS model run.

This report describes the optimization-based approach used by the Linking Tool in translating regional ReEDS CEM prescriptions to the PLEXOS PCM. The report focuses on the methods used for doing this translation and discusses the limitations and opportunities of the method. 


\section{Table of Contents}

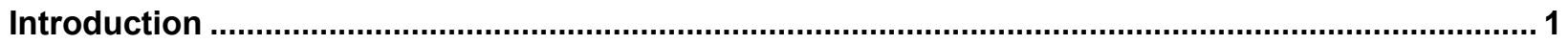

1 Linking Capacity Expansion with Production Cost Model: Approach......................................... 3

1.1 Capacity Expansion Model: ReEDS .......................................................................... 3

1.2 Production Cost Model: PLEXOS ............................................................................. 4

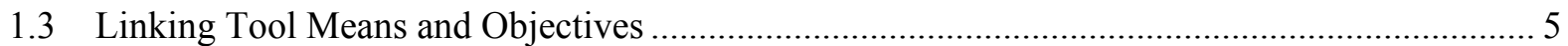

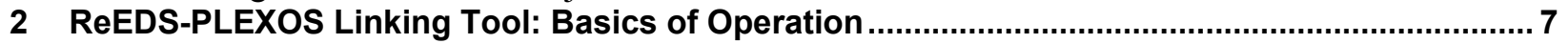

2.1 Onset of Ontologies via Optimization .................................................................. 7

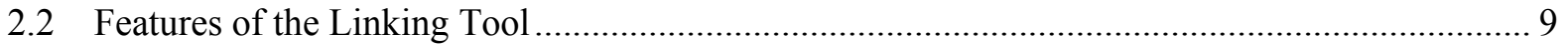

2.2.1 Small Units Aggregation ......................................................................... 9

2.2.2 PV, CSP, and Wind Generation Assignment in the Linking Tool ........................... 10

2.2.3 Transmission Expansion ............................................................................. 12

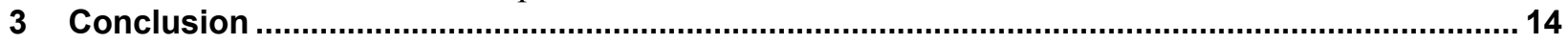

References .................................................................................................................................. 15

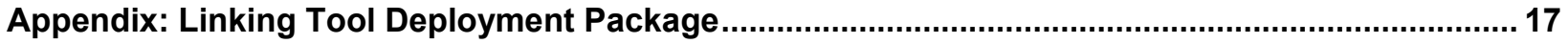

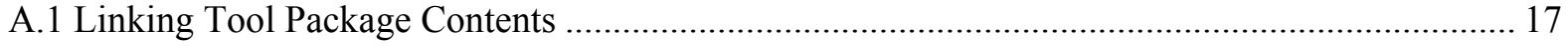

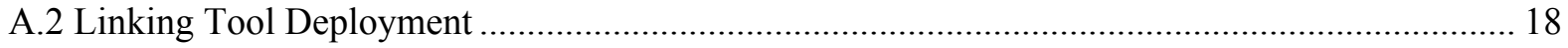

A.3 Using the Linking Tool................................................................................... 18

A.4 Improving the Linking Tool: Additional Units ......................................................... 21 


\section{List of Figures}

Figure 1. Sample ReEDS output showing the changing capacity mix over time ..................................... 3

Figure 2. Sample PLEXOS output: Aggregated optimal dispatch for the Western Interconnect ................. 4

Figure 3. Geospatial representation for the Western Interconnect......................................................... 7

Figure 4. Western Interconnect 30\% RPS ReEDS solution for the year 2050: Combustion turbines.......... 8

Figure 5. Aggregation of small regional assignments from ReEDS …............................................... 9

Figure 6. Selection of CSP resources in PLEXOS by the Linking Tool............................................ 10

Figure 7. Selection of PV resources in PLEXOS by the Linking Tool............................................... 11

Figure 8. Selection of wind resources by the Linking Tool ............................................................... 12

Figure 9. Regional interface shadow prices for standard (blue) and quick (red) PLEXOS runs............... 13

Figure 10. Transmission expansion as incremented interface limits .................................................... 13

Figure A1. Directory structure for a) the Linking Tool and b) the optimization/processing module ......... 17

Figure A2. The configuration batch file activates standard software packages...................................... 18

Figure A3. Sample ReEDS output file (left) and regional load data (right) formats ............................... 19

Figure A4. Example command window before (top) and after (bottom) executing the ruby_gams_activate

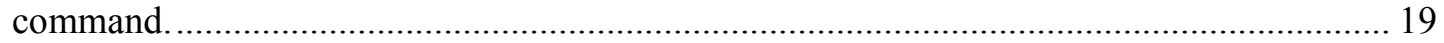

\section{List of Tables}

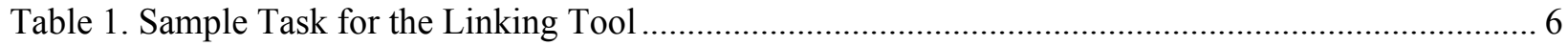

Table 2. Minimal Allowable Regional Capacity Levels (MW) ............................................................ 9 


\section{Introduction}

The power system continues to evolve, driven by changes in technology, policy, economics, and end-use demand (EIA 2015; Kassakian et al. 2011). Balancing authorities and utility companies are expanding (and rebuilding) their power generation fleets and considering new transmission lines and market structures. Capacity expansion and production cost models are often used to better understand the operation and planning of the power system.

Capacity expansion models (CEMs) provide a high-level, long-term view of the evolving power system. CEMs consider both operational and investment decisions within their modeling framework, and they thus help understand how the power system might evolve over time. Because of the computational challenges of joint simulation of both operational and investment decisions, CEMs generally do not model detailed system dispatch. Instead, they usually employ reduced-form dispatch models. Production-cost models (PCMs), on the other hand, typically have more detailed representations of system operations, but the system configuration is static (i.e., PCMs generally do not explicitly consider power system evolution). For example, CEMs may aggregate similar plants and simulate dispatch using a limited number of seasonal time slices while simultaneously determining optimal investments for new power plants over several decades, while PCMs may represent individual plants and simulate unit commitment and dispatch at a sub-hourly resolution for a single year using a static fleet.

Both tools can be very useful to decision makers, but the tools are designed to answer different types of questions. For example, a CEM may be used to understand how extending a renewable portfolio standard might drive new solar deployment, while a PCM might be employed to consider how increased solar deployment changes the amount of reserve capacity needed to keep the system stable.

CEMs and PCMs can also be used to inform one another. The SunShot Vision Study (DOE 2012) used a CEM to simulate how the grid might evolve given the SunShot Initiative's solar cost reduction targets, resulting in a future grid with significant solar generation. This future grid system was then represented in a PCM to simulate dispatch and verify the system feasibility in a simulated hourly environment and to better understand the system operation. Conversely, PCMs can also be used to inform input into CEMs. For example, PCM runs might be used to create generic inputs, such as minimum or maximum generation levels, that CEMs can use to better represent their reduced-form systems. Also, the importance of bridging PCM and CEM has been discussed when describing a "soft link" between the two types of models (Deane et al. 2012) and in a power sector expansion study for the Netherlands (Brouwer et al. 2015).

This work describes a tool that automates the linkage of a CEM and PCM. Specifically, this work focuses on taking CEM output from the Renewable Energy Deployment System (ReEDS) model and translating it into a PCM database for the PLEXOS production cost model using a platform we call the Linking Tool. ReEDS is an NREL-developed capacity expansion model (Short et al. 2011; Sullivan et al. 2015), and the production cost model (PLEXOS) is a commercial tool developed and licensed by Energy Exemplar LLC. This work represents an initial step in better using CEMs and PCMs to improve modeling, analysis, and decision-making, and it creates the foundation for making this type of linkage more robust. 
The Linking Tool modifies PLEXOS inputs so that they are consistent with ReEDS outputs. The approach is similar to the high-level-architecture method of combining computer models

(Dahmann et al. 1997); rather than having models communicate (i.e. exchange information) with each other, they only communicate with the "command center" (the Linking Tool, in this case). This approach is beneficial in that it allows other CEMs and PCMs to be linked using the same framework. In addition to information exchange with the models, the Linking Tool has another important role. ReEDS outputs and PLEXOS inputs are structured differently (e.g., aggregated vs. individual plant representations), and the Linking Tool "translate" one structure to another employing optimization methods. Currently, the Linking Tool is functional for the U.S. portion of the Western Interconnect; with additional work, it can be expanded to include ERCOT or the Eastern Interconnect. ${ }^{1}$

This report describes the Linking Tool and its principles of operation.

\footnotetext{
${ }^{1}$ Some level of work is required to get a PLEXOS database into a format that can be used by the Linking Tool. For example, the Linking Tool requires that a list of generators in PLEXOS be available in a format that can be read by GAMS (www.gams.com, accessed Nov 3, 2015).
} 


\section{Linking Capacity Expansion with Production Cost Model: Approach}

The approach used in developing the Linking Tool between ReEDS and PLEXOS is described in this section of the report. In its current state, the Linking Tool essentially translates ReEDS outputs into PLEXOS inputs: based on ReEDS outputs, the Linking Tool prepares a ready-to-use PLEXOS database.

\subsection{Capacity Expansion Model: ReEDS}

ReEDS is an electricity system capacity expansion model that develops scenarios of future investment and operation of generation and transmission capacity to meet U.S. electricity requirements. The model relies on system-wide, least-cost optimization to provide estimates of the type and regional location of fossil, nuclear, renewable, and storage resource development; the transmission infrastructure expansion requirements of those installations; and the generator dispatch and fuel needed to satisfy regional demand requirements and to maintain large-scale grid system adequacy. The model also considers technology, resource, and policy constraints, including state renewable portfolio standards. ReEDS models scenarios of the continental U.S. electricity system in two-year increments up to the year 2050. ReEDS scenarios provide a framework for exploring internally consistent future electricity systems (e.g., Figure 1) and for considering the potential impacts of technological development, policy changes, or economic conditions.

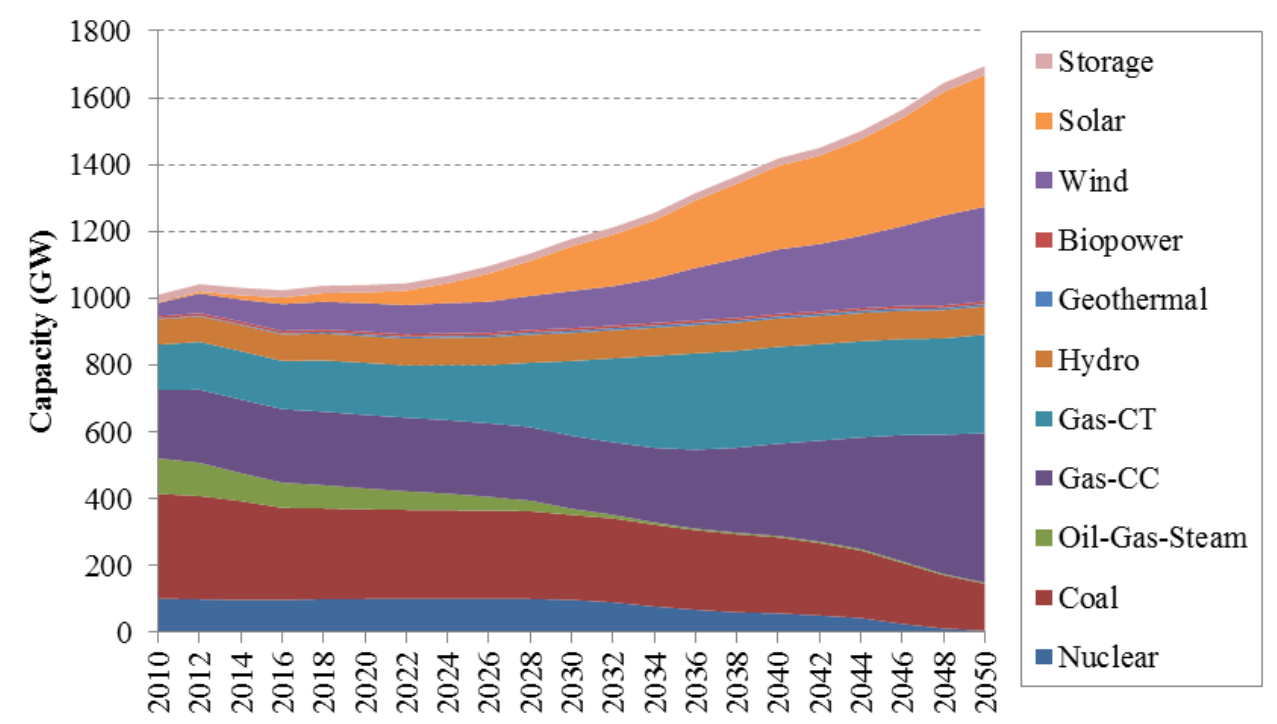

Figure 1. Sample ReEDS output showing the changing capacity mix over time

Source: Sullivan et al. 2015

ReEDS has been developed with an emphasis on characteristics important to renewable electricity technologies: variability, uncertainty, geographic resource specificity, and transmission. Its spatial resolution and statistical treatment of the impact of variable wind and solar resources enable representation of the relative value of geographically and temporally heterogeneous renewable power resources. While the emphasis is on renewable technologies, 
ReEDS includes a full suite of conventional generating technologies, a system dispatch that reveals seasonal and diurnal load shapes, a reduced transmission network, and dynamic capabilities for fuel supplies and electricity load.

At this time, the ReEDS outputs that are used by the Linking Tool are the location, type, and capacity of new and retired generators. ${ }^{2}$ Future work could incorporate other parameters, such as heat rates and fuel prices.

\subsection{Production Cost Model: PLEXOS}

The production cost model PLEXOS Integrated Energy Model is licensed by Energy Exemplar $\mathrm{LLC}^{3}$ and, in this work, is employed to simulate economic unit commitment and dispatch (Figure 2 ) in the Western Interconnect. The model minimizes production costs while accounting for temporal and geographic load distribution, generating units location and individual properties (e.g., startup/shutdown time, maximal generation capacity, minimum stable generation level, heat rate curve, minimum down time, variable operation and maintenance costs), and transmission limitations.

The Western Interconnect is a complex system ${ }^{4}$ and requires a detailed representation to be adequately simulated. To represent this system we rely on the Western Wind and Solar Integration Study (WWSIS) Phase 2 (Lew et al. 2013), where the Western Interconnect is represented in PLEXOS by the 2020 projections $^{5}$ of the Western Electricity Coordinating Council (WECC) Transmission Expansion Planning Policy Committee's (TEPPC) database (WECC 2011). ${ }^{6}$

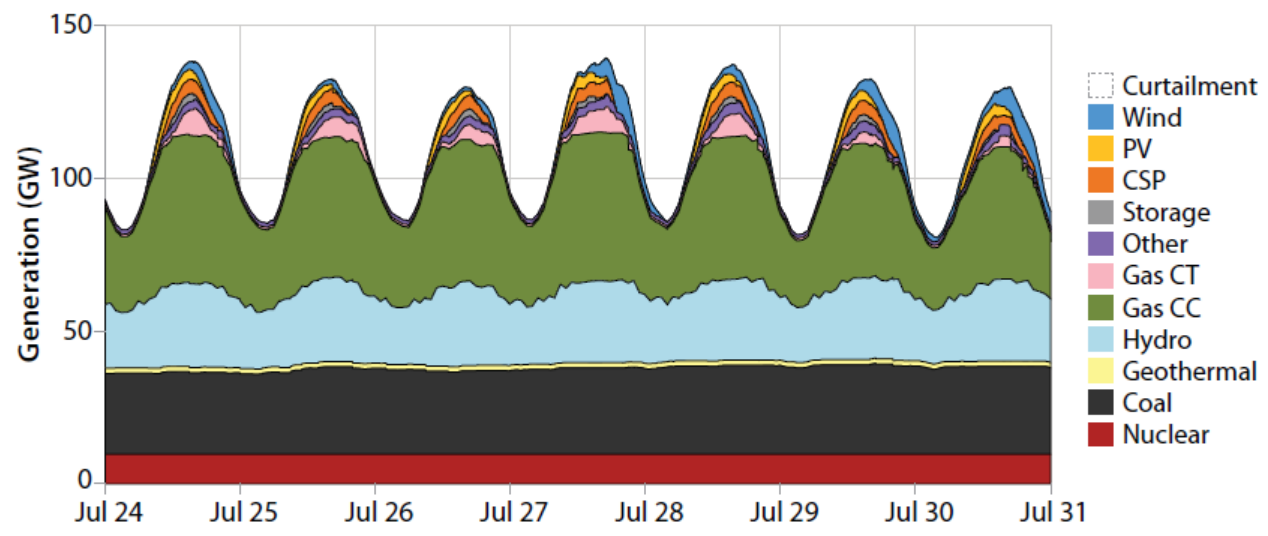

Figure 2. Sample PLEXOS output: Aggregated optimal dispatch for the Western Interconnect

Source: Lew et al. 2013

\footnotetext{
${ }^{2}$ In this work, the location is the ReEDS balancing area, the type is one of the generator types available in ReEDS, and the capacity is the summer nameplate capacity (for more information see Sullivan et al. 2015).

${ }^{3} \mathrm{http}$ ://energyexemplar.com/software/plexos-desktop-edition/, accessed Aug 07, 2015

${ }^{4}$ The system includes approximately 2,000 generating units and 17,000 nodes; the number of generating units changes after the ReEDS prescriptions are imposed on PLEXOS inputs.

${ }^{5}$ PLEXOS has also been used recently to study the Eastern Interconnect in the Eastern Renewable Grid Integration Study (ERGIS), but at the time of this writing final results of that study have not yet been released.

${ }^{6}$ The set of PLEXOS inputs describing an electric system is aggregated in a single database. In this case, the database characterizes the WECC electric system, as projected to 2020.
} 
In addition to the load and generating units database, solar and wind generators from the WWSIS database (Potter et al. 2013) are also included in the PLEXOS simulations of the Western Interconnect. When the Linking Tool imposes new capacity from ReEDS into the PLEXOS inputs, plant capacities are scaled. Heat rates and some other unit-specific inputs remain unchanged.

\subsection{Linking Tool Means and Objectives}

In linking capacity expansion with the production cost models the goal is to impose regional generation projections (capacity expansion model outputs) onto detailed, generator-by-generator, production cost model inputs. The production cost model PLEXOS is designed to function on a static database, ${ }^{7}$ so it does not allow including new generators. Existing generators, however, can be scaled easily, each by its own scaling factor. To help improve the matching between ReEDS outputs and PLEXOS inputs, we created "on-hold" generators that could be filled if new capacity was assigned to that region. For example, if ReEDS chooses to build a new gas plant in a region that has no gas plants, an "on-hold" gas plant can be used to represent the new gas plant from ReEDS. These on-hold generators were created for all technology types except for wind, PV, and concentrating solar power (generation from these three are location-specific so it is not possible to create representative generators that are location-neutral). The Linking Tool can switch the "on-hold" units on (their default state if "off"), scale the generators, and assign them to buses within their reserve region (the PLEXOS input database for the Western Interconnect has 10 reserve regions).

To illustrate how the Linking Tool works, it is convenient to consider the following example (summarized in Table 1). We examine a system that has three regions (A, B, C) and three photovoltaic (PV) generators (PV1 and PV11 in region $\mathrm{A}, \mathrm{PV} 2$ in region $\mathrm{B}$, and no generators in region $\mathrm{C}$ ), so that initially generation capacities in regions $\mathrm{A}, \mathrm{B}, \mathrm{C}$ are 70,10 , and $0 \mathrm{MW}$, respectively. Suppose the capacity expansion model assigns a different distribution of generating capacities between regions: 40, 20 and $10 \mathrm{MW}$ for regions $\mathrm{A}, \mathrm{B}$, and $\mathrm{C}$, respectively. The job of the Linking tool is to determine the best way of scaling these three generators to match the assigned regional capacity as closely as possible.

Since region $\mathrm{C}$ has no PV generators, an exact match of the assigned regional capacity distribution is impossible, and we have to prioritize the discrepancies. First, the overall (the sum over all three regions) should be met (in this example this condition can be satisfied). Second, the regional assignments should be met (this can be done for regions $\mathrm{A}$ or $\mathrm{B}$, but not $\mathrm{C}$ ). ${ }^{8}$ Third, the assigned $10 \mathrm{MW}$ for region $\mathrm{C}$ (that cannot be met by generation from this region) have to be compensated by an extra $10 \mathrm{MW}$ in either region A or B; it is preferable to place these extra 10 MW of generation in the geographically closest location; let us say region A is closer to $\mathrm{C}$ than region $\mathrm{B}$ and for this reason the extra $10 \mathrm{MW}$ capacity are placed in region A. Fourth, in deciding how the two generators from region A will be scaled to meet the new target $(40+10=50$

\footnotetext{
${ }^{7}$ There is also a capacity expansion version of PLEXOS, but that version is not considered in this work.

${ }^{8}$ For technologies other than wind, PV, and concentrating solar power (CSP), this condition will always be met because of the "on-hold" generators that were created. PV and CSP are handled as described here, while wind is handled using the method described in Section 2.2.2. PV and CSP cannot take advantage of the on-hold units because on-hold unit must be location agnostic while PV and CSP generation profiles are not.
} 
MW), we minimize changes to the original system (change being measured as how much the scaling factors differ from 1 , not counting scaling factors that are zero ${ }^{9}$ ). The result of successively applying the four priorities is shown in the bottom 4 rows of Table 1 .

Applying these four priorities translates regional capacity assignments to individual generator capacities. The algorithm is an optimization and has been implemented in the Linking Tool as a mixed integer program (MIP) with a weighted sum of multiple objectives (in order of priority): i) generation capacity balance over the entire Western Interconnect; ii) meeting regional capacity prescriptions; iii) if (ii) is not possible, comply with (i) by meeting regional requirements from closest neighboring regions; iv) if (i) and either (ii) or (iii) are met, minimize changes to the initial system. The algorithm constitutes the core of the Linking Tool and is applied separately to each generation type, in 30+ regions in the Western Interconnect that include thousands of generating units.

Table 1. Sample Task for the Linking Tool

\begin{tabular}{llll}
\hline Region & A & B & C \\
\hline PV1 initial capacity (MW) & 20 & & \\
\hline PV11 initial capacity (MW) & 50 & & \\
\hline PV2 initial capacity (MW) & & 10 & 0 \\
\hline Initial PV capacity in region (MW) & 70 & 10 & $\mathbf{1 0}$ \\
\hline Assigned regional capacity (MW) & $\mathbf{4 0}$ & $\mathbf{2 0}$ & \\
\hline PV1 assigned capacity (MW) & $0(=20 \times 0)$ & & \\
\hline PV11 assigned capacity (MW) & $50(=50 \times 1)$ & & $\mathbf{0}$ \\
\hline PV2 assigned capacity (MW) & & $20(=10 \times 2)$ & \\
\hline Resulting regional capacity (MW) & $\mathbf{5 0}$ & $\mathbf{2 0}$ &
\end{tabular}

The next section discusses the Linking Tool approach more generally. Practical aspects of using the Linking Tool (software package, deployment, and operation) are discussed in the appendix.

\footnotetext{
${ }^{9}$ By not penalizing scaling factors equal to zero, retirements are allowed.
} 


\section{ReEDS-PLEXOS Linking Tool: Basics of Operation}

When translating ReEDS outputs to PLEXOS inputs, the Linking Tool uses optimization methods. The optimization sets the correspondence between the differently structured data sets. One of the simplest examples that sets data correspondence via optimization is the least-squares method (e.g., a straight line is "imposed" on a set of points on a geometric plane) (Legendre 1805). ReEDS and PLEXOS data show more complexity than a straight line and points on a plane. Hence, the optimization methods are more sophisticated. We have developed an optimization approach (briefly described in the previous section) which is repeatedly employed in the Linking Tool and can be used in other computational applications as well. For brevity, the approach will be referred to as the onset of ontologies ${ }^{10}$ via optimization (OOO) and is discussed below.

\subsection{Onset of Ontologies via Optimization}

One of the most important differences between ReEDS and PLEXOS description of the electric power system is the level of detail (Figure 3). ReEDS operates at regional level (there are 35 ReEDS regions that cover the Western Interconnect), while PLEXOS can operate at bus level (with over 17,000 buses in the Western Interconnect database); also, ReEDS uses 17 time slices to simulate system dispatch, and PLEXOS provides sub-hourly simulation of the electric system operation.
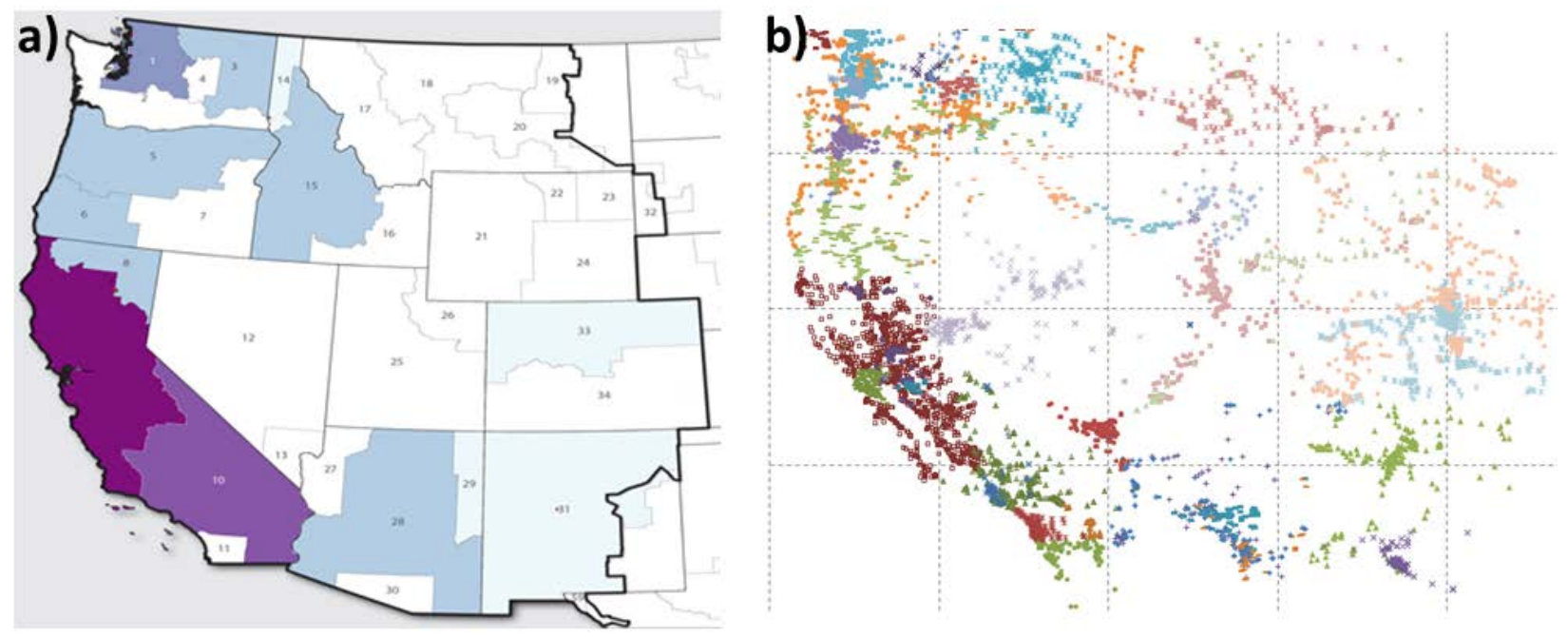

Figure 3. Geospatial representation for the Western Interconnect

a) ReEDS regions: numbered and differ in colors

b) PLEXOS buses: represented as points, balancing authorities differ in colors

The production cost model offers a more detailed description of the power system and, for this reason, multiple possibilities in accommodating regional prescriptions from ReEDS. To avoid ambiguity, additional criteria are used in down-selecting (from regional to plant level) generation units, as briefly shown in the example given in Section 1.3.

\footnotetext{
${ }^{10}$ Differently organized data structures are sometime called ontologies (Talk et al. 2013)
} 
The set of generating units in the Western Interconnect PLEXOS model, although significantly more detailed than regional data from ReEDS, may not satisfy regional prescriptions with complete accuracy (for example, when a region entirely lacks generators of a given type). In these cases, similar to the example from Section 1.3, the Linking Tool compensates for the missing capacity with extra generators from neighboring regions (from the closest regions with available generating capacity, Figure 4) and minimizes the amount and the distance of the "borrowed" capacity.

The PLEXOS database for the Western Interconnect was vetted independently from ReEDS and is often used separately. To "inherit" as many features of this database as possible, it is reasonable to limit (where possible) the ReEDS-induced changes to the database. For this purpose, the Linking Tool (within the OOO approach) inflicts a penalty on changing a generator capacity and an extra penalty for increasing generator capacity more than fourfold ${ }^{11}$ over its initial value in the database.

To summarize: the Linking Tool employs OOO, which involves a) minimizing discrepancies between the high level prescriptions (ReEDS) and the broader detailed data set (PLEXOS); b) applying additional criteria (e.g., higher capacity factors when choosing wind or PV generators; see Section 2.2.2) and keeping changes at minimum where the detailed data set allows a diversity of choices.

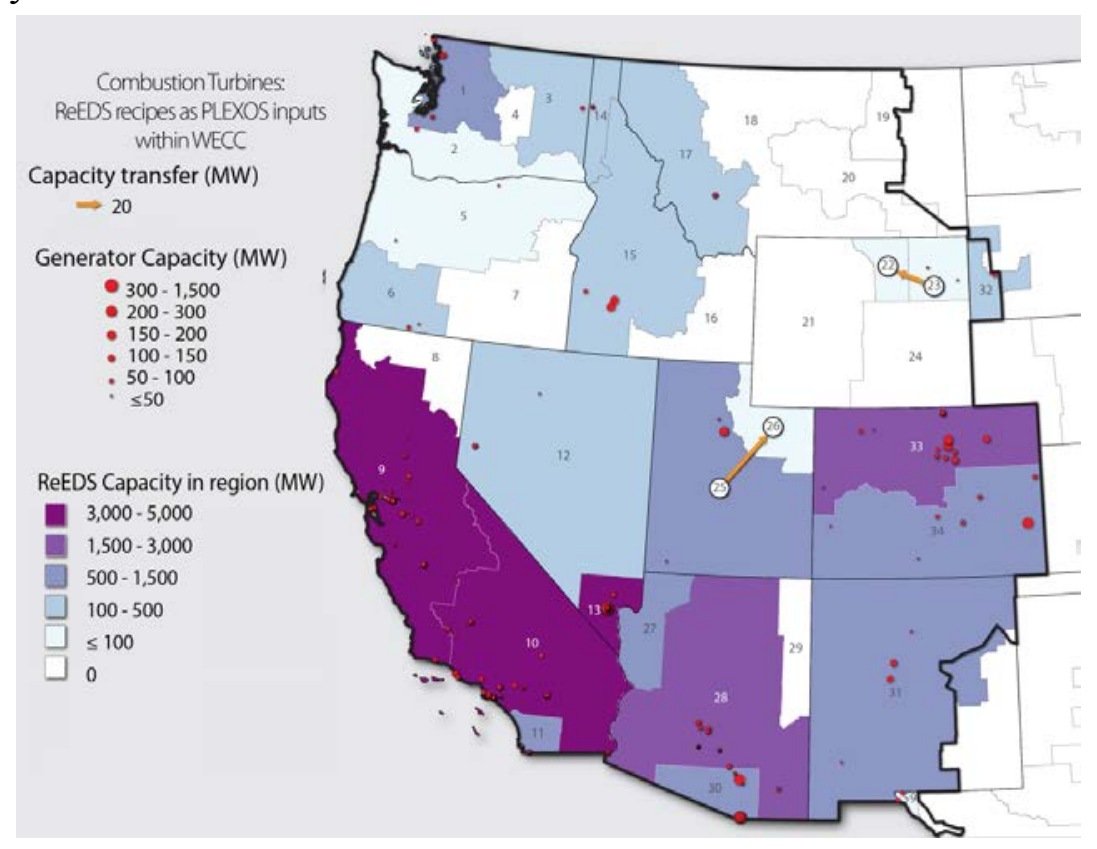

Figure 4. Western Interconnect 30\% RPS ReEDS solution for the year 2050: Combustion turbines

Red circles show CT units selected from PLEXOS database by the Linking Tool, according to ReEDS prescriptions. The latter are used to color-code the regions. The arrows indicate that region "26" is "borrowing" capacity from region "25" in Utah, and region "22" from "23" in Montana. With the addition of "on-hold" units (see the appendix, Section A.4), the CT capacity "borrowing" is eliminated.

\footnotetext{
${ }^{11}$ This and other thresholds with corresponding penalties can be employed depending on how "radically" ReEDS outputs modify the starting database. The penalties can be adjusted by the user.
} 


\subsection{Features of the Linking Tool}

\subsubsection{Small Units Aggregation}

When ReEDS regional prescriptions include small regional generation capacity values, it is desirable to aggregate them to more reasonable levels. For example, because ReEDS is a linear model and therefore cannot have minimum system size constraints, it may choose to build a 1 MW combined-cycle natural gas plant. The Linking Tool includes the capability to aggregate small builds into larger units. Minimal allowable regional capacity levels used by the Linking Tool are shown in Table 2, though these values are customizable by the user. The aggregation of small regional prescription values can be considered as a pre-processing of ReEDS outputs. It does not affect the functionality of the rest of the Linking Tool.

Table 2. Minimal Allowable Regional Capacity Levels (MW)

\begin{tabular}{llllll}
\hline Generation Type & Coal & CC & CT & Biomass & Geothermal \\
\hline Region minimal capacity (MW) & 100 & 50 & 20 & 5 & 7 \\
\hline
\end{tabular}

An example of ReEDS outputs aggregation is given in Figure 5. The column labeled "PCA" denotes the ReEDS regions, and "_xtr" and "_ndr" indicate excess and deficit capacity, respectively, compared to the non-aggregated ReEDS output. In this example, combined cycle (CC) regional assignments need no aggregation; small combustion turbines (CT) assignments are aggregated to neighboring regions ( $0.4 \mathrm{MW}$ for Region 19 is aggregated to Region 17), some fractions of larger regional assignments (5 MW from Region 23 and 7.65 MW from Region 25) are increasing neighboring region assignments to the minimal level (Regions 22 and 26, respectively).

\begin{tabular}{|c|c|c|c|c|c|c|}
\hline 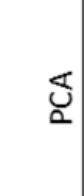 & 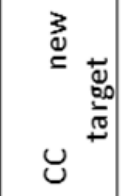 & $\overrightarrow{\vec{x}}$ & 흘. & 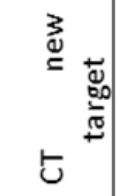 & $\frac{\dot{z}}{x}$ & $\stackrel{t}{c}$ \\
\hline 1 & 944.1 & 0 & 0 & 548 & 0 & 0 \\
\hline 14 & 248 & 0 & 0 & 132 & 0 & 0 \\
\hline 15 & 319.09 & 0 & 0 & 411 & 0 & 0 \\
\hline 16 & 0 & 0 & 0 & 0 & 0 & 0 \\
\hline 17 & 0 & 0 & 0 & 184.45 & 0.4 & 0 \\
\hline 18 & 0 & 0 & 0 & 0 & 0 & 0 \\
\hline 19 & 0 & 0 & 0 & 0 & 0 & 0.4 \\
\hline 20 & 0 & 0 & 0 & 0 & 0 & 0 \\
\hline 21 & 0 & 0 & 0 & 0 & 0 & 0 \\
\hline 22 & 0 & 0 & 0 & 20 & $=5$ & 0 \\
\hline 23 & 0 & 0 & 0 & 93 & 0 & 5 \\
\hline 24 & 0 & 0 & 0 & 0 & 0 & 0 \\
\hline 25 & 1227 & 0 & 0 & 532.85 & 0 & 7.65 \\
\hline 26 & 0 & 0 & 0 & $20<$ & -7.65 & -0 \\
\hline
\end{tabular}

Figure 5. Aggregation of small regional assignments from ReEDS

The arrows indicate regional assignments that are aggregated to neighboring regions. 


\subsubsection{PV, CSP, and Wind Generation Assignment in the Linking Tool}

For the same ReEDS scenario as in Figure 4, the sets of concentrating solar power (CSP) and PV generators selected by the Linking Tool are shown in Figures 6 and 7, respectively. In both cases, the Linking Tool could not match the ReEDS outputs exactly, resulting in relatively small generating capacities being placed in the neighboring regions.

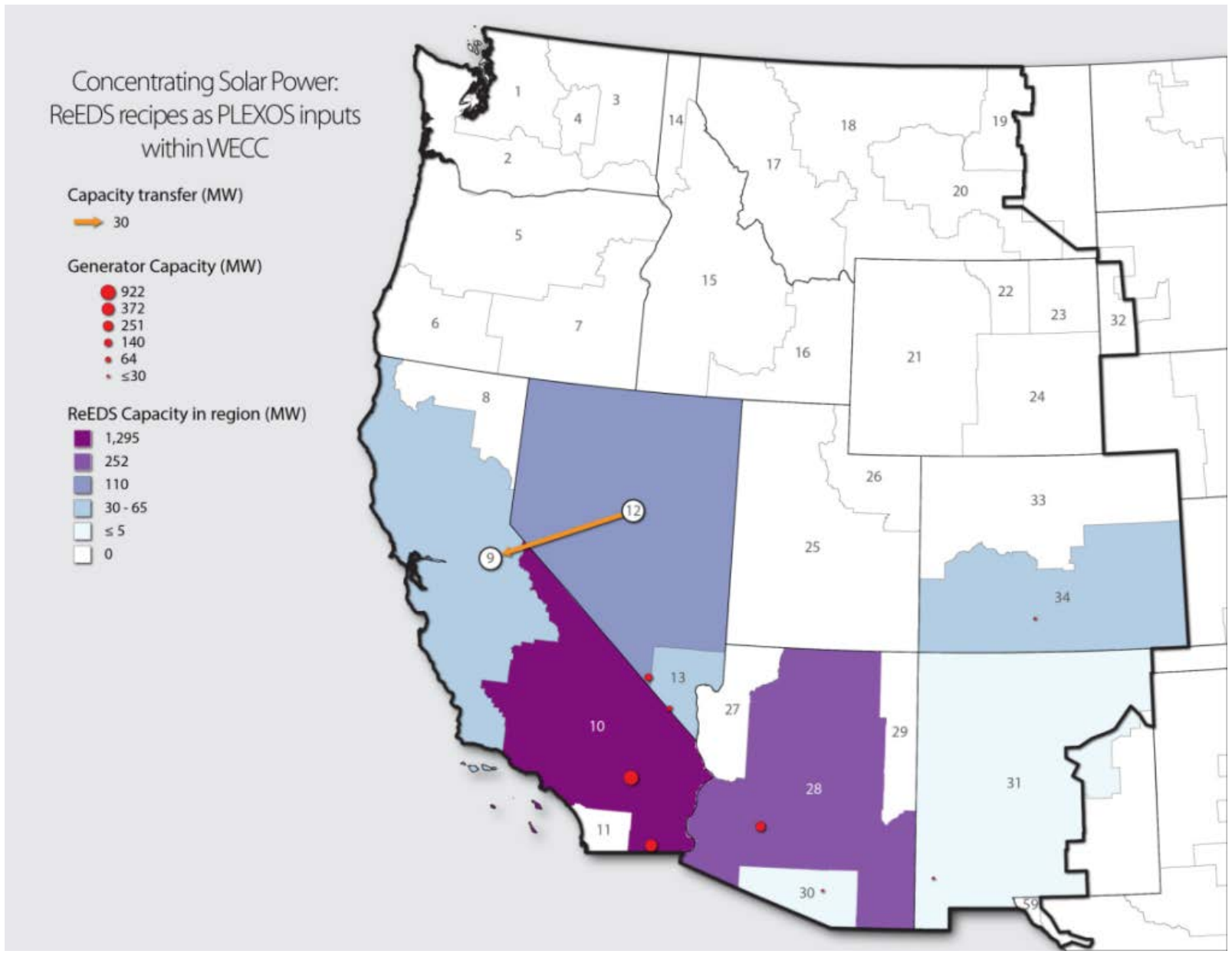

Figure 6. Selection of CSP resources in PLEXOS by the Linking Tool

The CSP capacity assigned by ReEDS to Northern California (Region 9) is compensated by an extra $30 \mathrm{MW}$ of CSP capacity from Nevada (Region 12). 


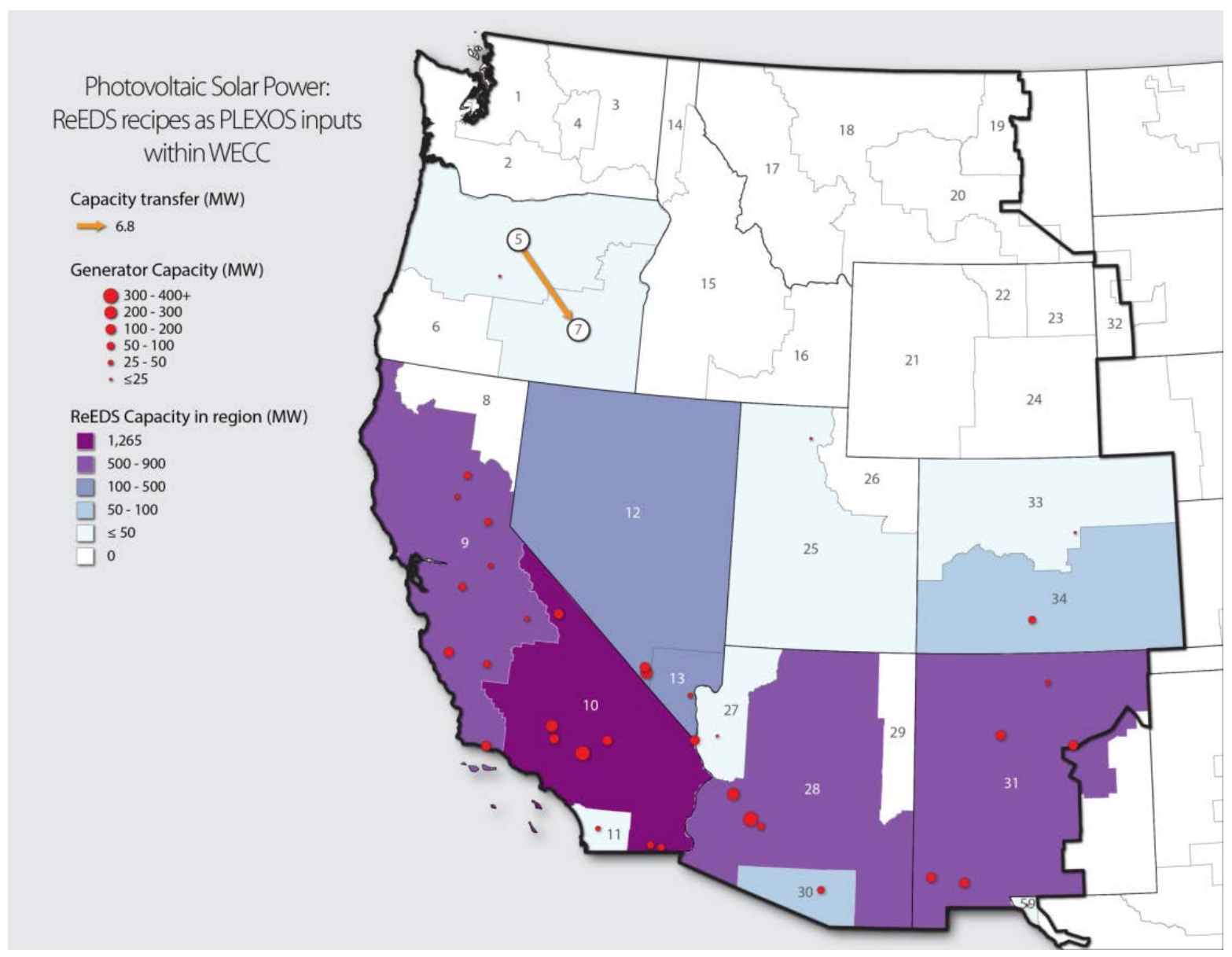

Figure 7. Selection of PV resources in PLEXOS by the Linking Tool

6.8 MW of PV capacity assigned by ReEDS to Region 7 is compensated by extra capacity from Region 5 .

The Western Interconnect database used by the Linking Tool contains about 500 PV generating units and close to 100 wind generators. To further diversify the set of available wind generators, the entire WWSIS database (30,000 generating sites, Potter et al. 2008) is incorporated in the Linking Tool. ${ }^{12}$ The Linking Tool matches ReEDS regional prescriptions by selecting the WWSIS wind sites. The WWSIS wind sites have a broad representation in all ReEDS regions and the ReEDS solution is matched exactly. To incorporate the selected WWSIS wind sites (typically, more than a thousand) in the PLEXOS database, they are further aggregated (with their generation profiles) to the closest wind generator from PLEXOS. The results are shown in Figure 8.

\footnotetext{
${ }^{12}$ The set of available PV generators can be expanded as well when a similar solar database becomes available. Solar resources, however, tend to have less spatial variability compared to wind resources, and the 500 sites currently available are sufficiently diverse to capture much of the solar resource variation in the Western Interconnect.
} 


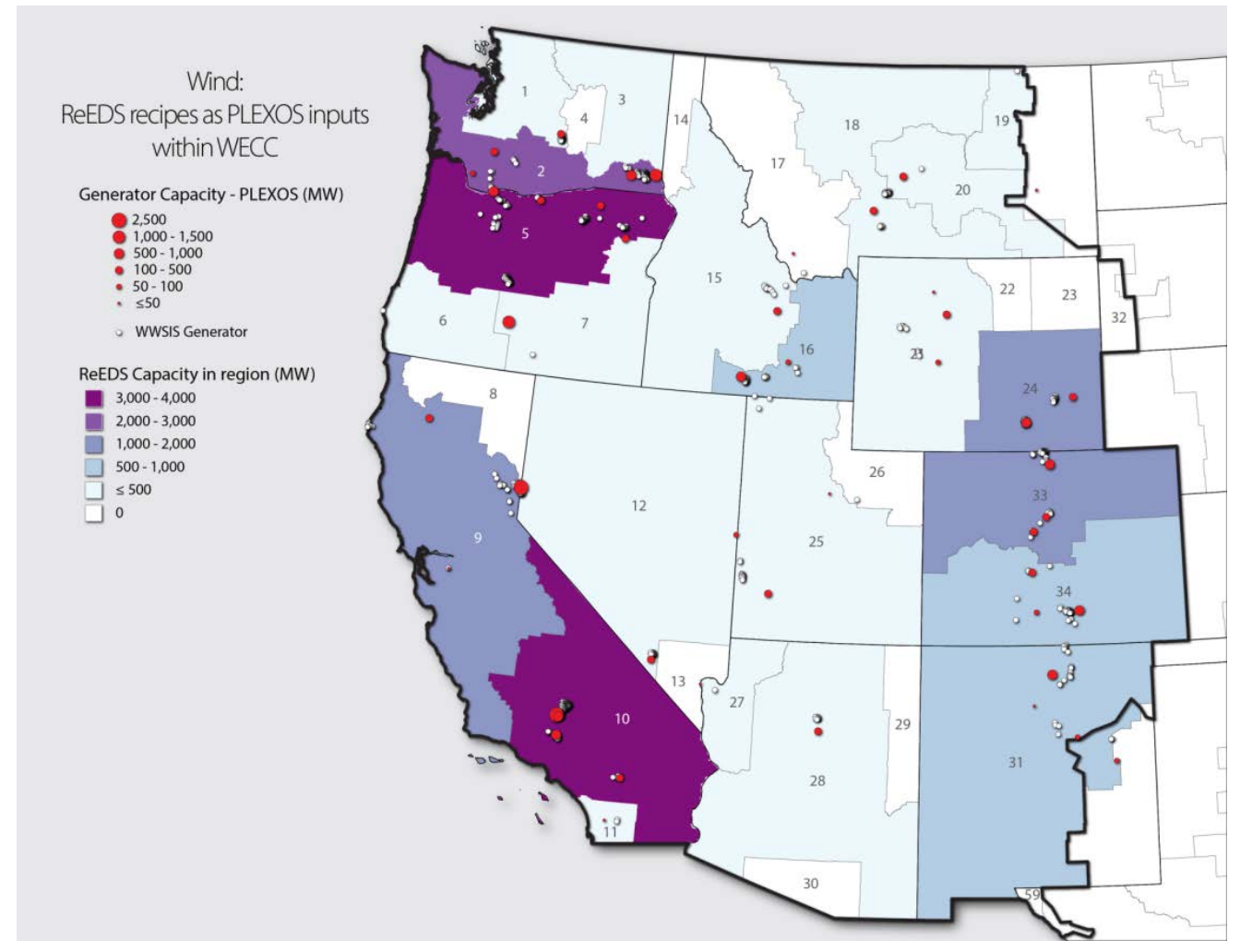

Figure 8. Selection of wind resources by the Linking Tool

Wind generators from the WWSIS database (open symbols) are selected to match regional ReEDS prescriptions. Further, these WWSIS generators are aggregated to the nearest PLEXOS wind generators (red circles).

\subsubsection{Transmission Expansion}

Transmission expansion within the Linking Tool follows the framework outlined in the WWSIS2 study (Lew et al. 2013). Only regional interface limits are involved. A similar regional approach to transmission expansion is described in EPRI (2015). The goal is to create a selfconsistent PLEXOS database. Consistency with ReEDS transmission expansion predictions is not part of this goal. The transmission expansion procedure described here is affected by the ReEDS solution only in that it is driven by ReEDS generation capacity expansion prescriptions. The reason for not relying on the ReEDS transmission outputs is that ReEDS and PLEXOS do not have identical regions or transmission representation, and there currently is no method to translate ReEDS transmission builds directly to PLEXOS. ${ }^{13}$

The Linking Tool procedure for transmission build-out involves iterative PLEXOS runs and can be time consuming. The transmission interface limits are increased if their shadow price exceeds a threshold. The interface limits are increased in steps of $500 \mathrm{MW}$ while the shadow price threshold is gradually decreased from 20 to $5 \$$ MWh. The steps outlined in Section 3 of the appendix reduce the computation time without significantly affecting the transmission expansion

\footnotetext{
${ }^{13}$ Because ReEDS uses a different transmission expansion method than the Linking Tool, the final transmission expansion results are likely to be different.
} 
results. Figure 9 verifies this simplification by comparing shadow prices for interfaces in the two PLEXOS ${ }^{\mathrm{TM}}$ simulations: the "standard" time-consuming approach and the faster approach (simplified according to Section 3 of the appendix, item v). The average shadow prices are close for most interfaces, which validates the more tractable approach.

The transmission expansion iterative procedure completed in less than 24 hours and the results are presented in Figure 10.

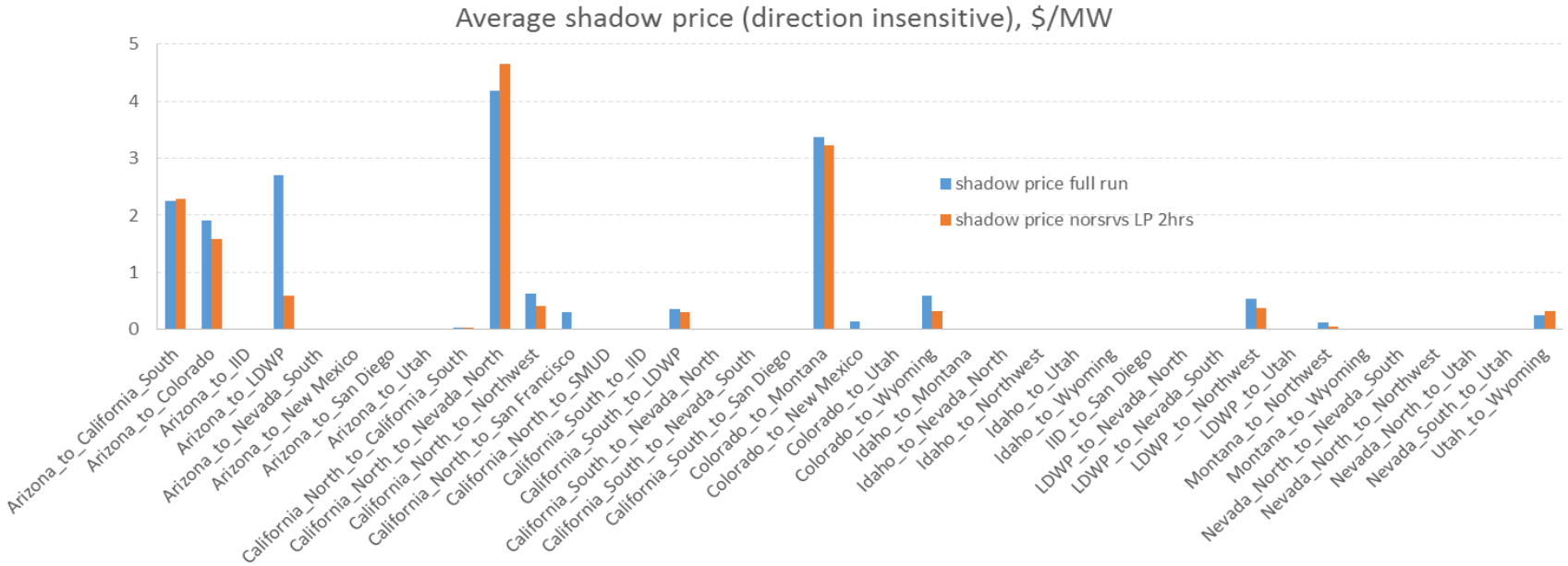

Figure 9. Regional interface shadow prices for standard (blue) and quick (red) PLEXOS runs.

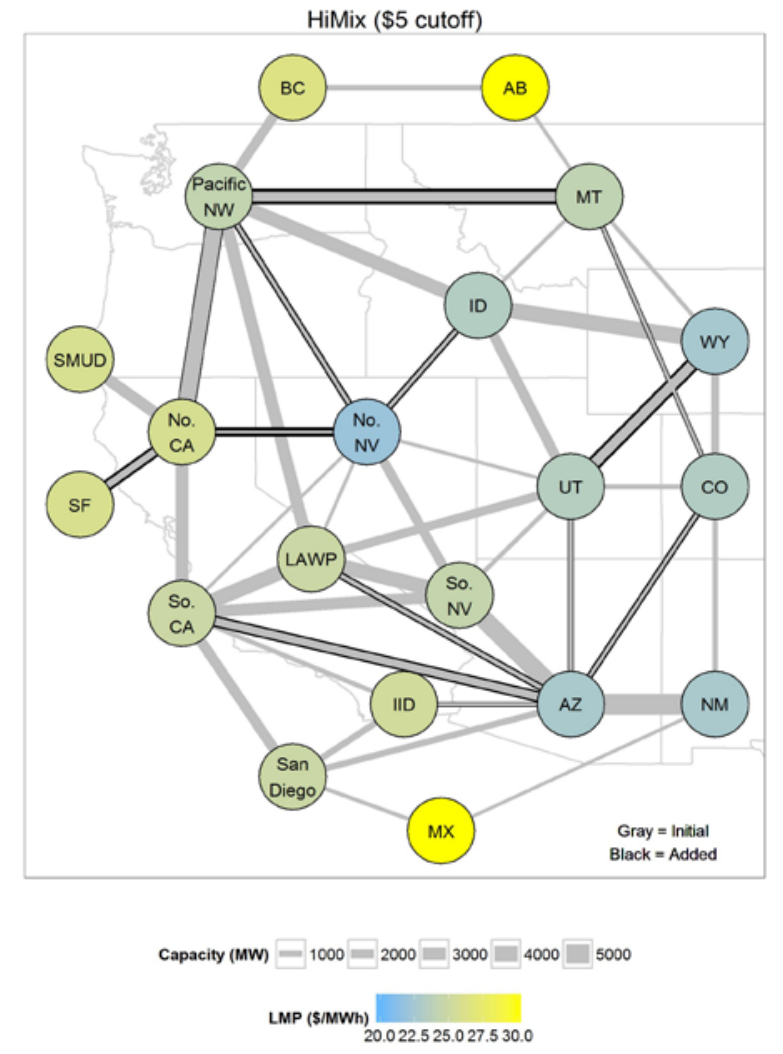

Figure 10. Transmission expansion as incremented interface limits The bands with black borders indicate increased interface limits. 


\section{Conclusion}

This report describes the operational capabilities of the ReEDS-PLEXOS Linking Tool. The Linking Tool provides validation of ReEDS scenarios on a more detailed level, and generation of evolutionary sound PLEXOS cases. The basic logic and functionality of the Linking Tool could be readily applied to linking other CEMs and PCMs, A description of the Linking Tool deployment package is given in the appendix. The Linking Tool may also be useful in exploring a number of questions related to power system evolution. For example, the tool can be used to examine the effect of different criteria for choosing wind and PV generators from the available pool at high levels of renewables in the system (the effect may be significant; see Diakov 2015). The Linking Tool could also be used to examine the detailed system response to various policy incentives.

In addition to future power systems analysis work, the functionality of the Linking Tool could be improved in several ways. Future developments could include expanding the solar resource data set to the full Solar Integration National Dataset (NREL 2015), which would allow for a better characterization of solar generators in PLEXOS, similar to the way the WWSIS wind generators database is incorporated in the Linking Tool. Another potential valuable addition would be to develop a method for downscaling large-scale transmission expansion to changes in individual transmission lines.

Also, the Linking Tool can be expanded in several directions. Geographically, the Eastern Interconnect and ERCOT databases of PLEXOS inputs would complete the contiguous U.S. expansion scenarios from ReEDS. Other capacity expansion models (such as the Resource Planning Model; see Mai et al. 2013) could be bridged with PLEXOS via the Linking Tool. Finally, production cost models other than PLEXOS could be bridged with capacity expansion models using the methodology developed in the Linking Tool. 


\section{References}

Brouwer, Anne Sjoerd, Machteld van den Broek, Ad Seebregts, and André Faaij. 2015. "Operational Flexibility and Economics of Power Plants in Future Low-carbon Power Systems." Applied Energy 156: 107-128.

Dahmann, J. S., R. Fujimoto, and R. M. Weatherly. 1997. "The Department of Defense High Level Architecture." Proceedings of the 1997 Winter Simulation Conference, eds. S. G. Henderson, B. Biller, M. Hsieh, J. Shortle, J. D. Tew, R. R. Barton; 142-149. Piscataway, New Jersey: Institute of Electrical and Electronics Engineers, Inc.

Deane J.P., Alessandro Chiodi, Maurizio Garguilo, and Brian P. Ó Gallachoir. 2012. "Softlinking of a Power Systems Model to an Energy Systems Model.” Energy 42: 303-312.

Diakov, Victor. 2015. "Wind Resource Quality Affected by High Levels of Renewables" Resources 4: 378-383.

DOE (U.S. Department of Energy). 2012. SunShot Vision Study. U.S. Department of Energy. http://energy.gov/eere/sunshot/sunshot-vision-study. Accessed September 24, 2015.

EIA (U.S. Energy Information Administration). 2015. Annual Energy Outlook 2015. U.S. Energy Information Administration.http://www.eia.gov/forecasts/aeo/executive_summary.cfm, Accessed August 26, 2015.

EPRI (Electric Power Research Institute). 2015. US-REGEN Unit Commitment Model Documentation. Principal Investigators J. Bistline, G. Blanford, D. Young, V. Niemeyer, F. de la Chesnaye, T. Wilson. Palo Alto, CA: EPRI. 2015:3002004748. http://www.epri.com/abstracts/Pages/ ProductAbstract.aspx?ProductId=000000003002004748. Accessed September 15, 2015.

Kassakian, John G., Richard Schmalensee, Gary Desgroselliers, Timothy D. Heidel, Khurram Afridi, Amro M. Farid, Jerrold M. Grochow, William W. Hogan, Henry D. Jacoby, James L. Kirtley, Harvey G. Michaels, Ignacio Perez-Arriaga, David J. Perreault, Nancy L. Rose, Gerald L. Wilson, Nabi Abudaldah, Minjie Chen, Pearl E. Donohoo, Samantha J. Gunter, P. Jordan Kwok, Vivek Sakhrani, Jiankang Wang, Andrew Whitaker, Xiang Ling Yap, and Richard Y. Zhang. 2011. The Future of the Electric Grid: An Interdisciplinary MIT

Study. http://mitei.mit.edu/system/files/Electric_Grid_Full_Report.pdf. Accessed August 26, 2015.

Legendre, Adrien-Marie . 1805. Nouvelles Méthodes pour la Détermination des Orbites des Comètes. Paris: F. Didot.

Lew, D., G. Brinkman, E. Ibanez, A. Florita, M. Heaney, B.-M. Hodge, M. Hummon, G. Stark, J. King, S.A. Lefton, N. Kumar, D. Agan, G. Jordan, and S. Venkataraman. 2013. The Western Wind and Solar Integration Study Phase 2. Golden, CO: National Renewable Energy Laboratory. NREL/TP-5500-55588. 
Mai, T, Easan Drury, Kelly Eurek, Natalie Bodington, Anthony Lopez, and Andrew Perry. 2013. Resource Planning Model: An Integrated Resource Planning and Dispatch Tool for Regional Electric Systems. Golden, CO: National Renewable Energy Laboratory. NREL/TP-6A20-56723.

NREL (National Renewable Energy Laboratory. 2015. Solar Integration National Dataset (SIND) Toolkit. Computer program. http://www.nrel.gov/electricity/transmission/ sind toolkit.html Accessed August 26, 2015.

Potter, Cameron W., Debra Lew, Jim McCaa, Sam Cheng, Scott Eichelberger, and Eric Grimit. 2008. "Creating the Dataset for the Western Wind and Solar Integration Study (USA)." Wind Engineering 32(4): 325-338.

Short, Walter, Patrick Sullivan, Trieu Mai, Matthew Mowers, Caroline Uriarte, Nate Blair, Donna Heimiller, and Andrew Martinez. 2011. Regional Energy Deployment System (ReEDS). Golden, CO: National Renewable Energy Laboratory. NREL/TP-6A20-46534.

Sullivan, Patrick, Wesley Cole, Nate Blair, Eric Lantz, Venkat Krishnan, Trieu Mai, David Mulcahy, and Gian Porro. 2015. 2015 Standard Scenarios Annual Report: U.S. Electric Sector Scenario Exploration. Golden, CO: National Renewable Energy Laboratory. NREL/TP-6A2064072.

Tolk, Andreas, Brian L. Heath, Martin Ihrig, Jose J. Padilla, Ernest H. Page, E. Dante Suarez, Claudia Szabo, and Paul Weirich, L. Yilmaz. 2013. "Epistemology of Modeling and Simulation." Proceedings of the 2013 Winter Simulation Conference, eds. R. Pasupathy, S.-H. Kim, A. Tolk, R. Hill, and M. E. Kuhl; pp. 1152-1166.

WECC (Western Electricity Coordinating Council). 2011. 10-year Regional Transmission Plan. https://www.wecc.biz/Reliability/2011_Plan_Summary.pdf. Accessed August 07, 2015. 


\section{Appendix: Linking Tool Deployment Package}

The deployment package for the Linking Tool was developed by the Energy Forecasting and Modeling Group within NREL's Strategic Energy Analysis Center. A GAMS license is required to operate the Linking Tool. While the Linking Tool was designed to specifically link ReEDS and PLEXOS, the approach and methods used can be applied more broadly to convert capacity expansion modeling results to production cost models.

\section{A.1 Linking Tool Package Contents}

The contents of the Linking Tool come in one directory, reeds2plex_main, which contains compressed directories and comments on how to un-compress them. The package (directories structure shown in Figure A1) includes:

i) standard software (GAMS version 23.9, R version 3.1.2, Ruby version 185.24),

ii) in the reeds2plex directory, original software developed to support the Linking Tool (also shown in more detail on Figure A1b),

1) the reeds2plex_gams directory contains the optimization module, and

2) reeds 2 plex_dbhandling directory processes the PLEXOS input database according to the optimization results;
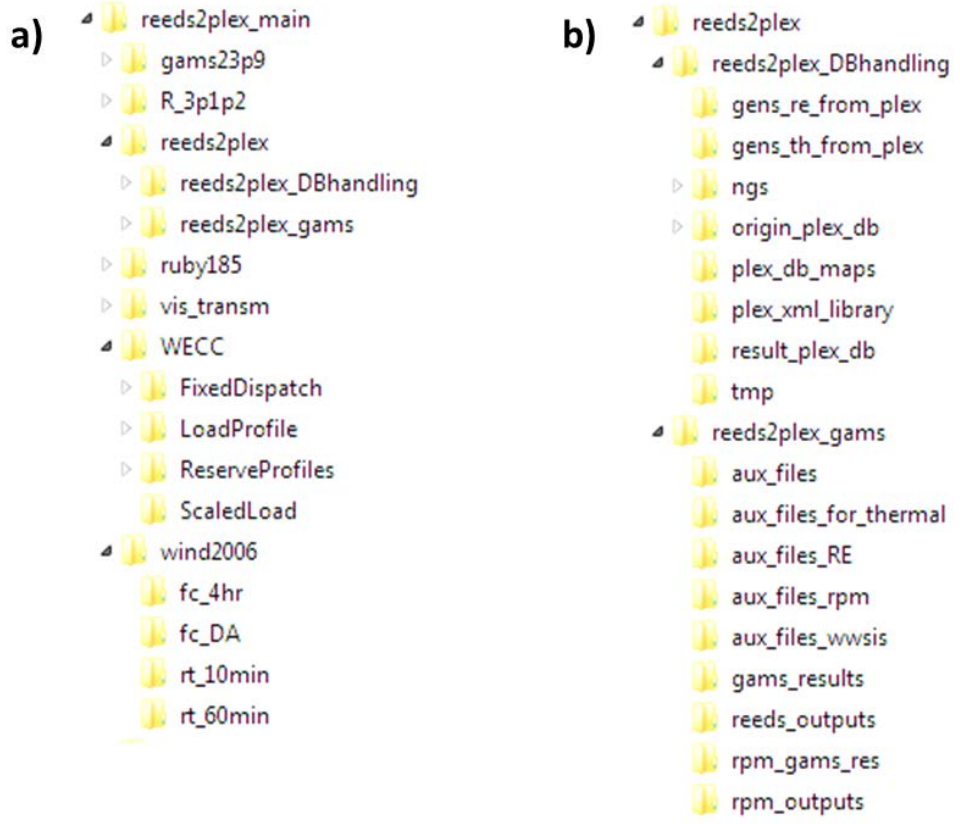

Figure A1. Directory structure for a) the Linking Tool and b) the optimization/processing module

iii) WWSIS wind generation data for 2006 (formatted for PLEXOS use, wind2006 and wind2006zip directories)

iv) $\quad W E C C$ is the PLEXOS working directory, contains parts that are referenced from the PLEXOS input database. 


\section{A.2 Linking Tool Deployment}

To deploy the Linking Tool,

i) the user copies the contents of the package to the convenient location on the hard drive (the compressed package "weighs" about 7 GB).

ii) un-compresses the contents of $r 2 p \_$main to the same folder (so that directories gams $23 p 9$, ruby 185 would share the same directory level with wind2006, as in Figure A1a).

iii) un-compresses the contents of wind2006 directory following the instructions from the wind2006|readme.txt.

iv) in the top-level directory (reeds2plex_main on Figure A1a), the configuration batch file ruby_gams_activate needs corrections that depend on the location where the package is deployed: the right-hand-side of the "set" statement (Figure A2) should show the path to the main Linking Tool folder (coincides with the location of the batch file, in this case).

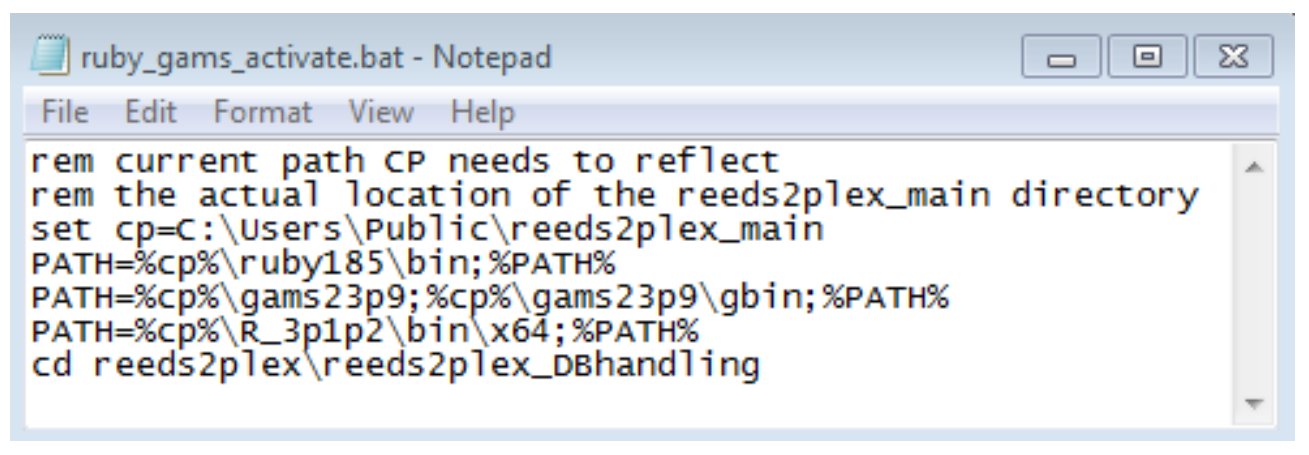

Figure A2. The configuration batch file activates standard software packages

The third line ("set $c p=\ldots$ ") points to the location of the Linking Tool.

In its working (un-compressed) state, the package takes approximately $20 \mathrm{~GB}$ of hard drive space.

\section{A. 3 Using the Linking Tool}

After deployment, the following steps need to be taken to onset ReEDS outputs to PLEXOS:

i) ReEDS outputs should be placed in the reeds2plex|reeds2plex_gams|reeds_outputs directory in a CSV file named RPS80_WECC2.csv. The format of the ReEDS output csv file is shown in Figure A3, top. The top row denotes generation technology, ReEDS region, projection year, old capacity, new installed capacity, retired capacity, net capacity (MW) and heat rate (thousand Btu/kWh). Currently, the Linking Tool only uses columns "tech" (technology, or type of power generation), "n" (ReEDS region), "year" (ReEDS projections year), and "net.cap" (net capacity, MW, takes into account retirements and new builds). 
a. In addition, ReEDS load data for all ReEDS regions need to be placed in the same directory in a regional load for the year (MWh), csv file named

ReferenceDemand.csv (Figure A3). The field "value" shows annual load by ReEDS region and year (MWh).

ii) In the MS-DOS - type command window, navigate to the location of the Linking Tool (Figure A4, top). The ruby_gams_activate command will activate GAMS and ruby packages for the currently open command window, and will navigate to the working directory of the Linking Tool: reeds2plex|reeds2plex_DBhandling. If the machine hosting the Linking Tool does have ruby and GAMS installed, the user can skip running ruby_gams_activate command and just navigate to the working directory of the Linking Tool (Figure A4, bottom).

iii) In the working directory of the Linking Tool (reeds2plex|reeds2plex_DBhandling), using a text editor, in the file year.rb, set the year for the desired PLEXOS simulation. The default year is 2050 .

\begin{tabular}{|c|c|c|c|c|c|c|c|c|c|c|c|c|}
\hline 4 & A & B & C & D & E & $\mathrm{F}$ & G & H & $\Delta$ & A & B & $\mathrm{C}$ \\
\hline 1 & tech & $n$ & year & old.cap & new.cap & retired.cap & et.cap & hr & 1 & year & $\mathrm{n}$ & value \\
\hline 2 & Biopower & & 2010 & 97 & 0 & 0 & 97 & 12.59 & 2 & 2010 & p1 & 49562597 \\
\hline 3 & Biopower & & 2012 & 97 & 0 & 0 & 97 & 12.59 & 2 & 2010 & & 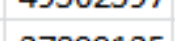 \\
\hline 4 & Biopower & & 2014 & 97 & 0 & 0 & 97 & 12.59 & 3 & 2010 & p2 & 27899125 \\
\hline 5 & Biopower & p1 & 2016 & 97 & 0 & 0 & 97 & 12.59 & 4 & 2010 & p3 & 12718081 \\
\hline
\end{tabular}

Figure A3. Sample ReEDS output file (left) and regional load data (right) formats

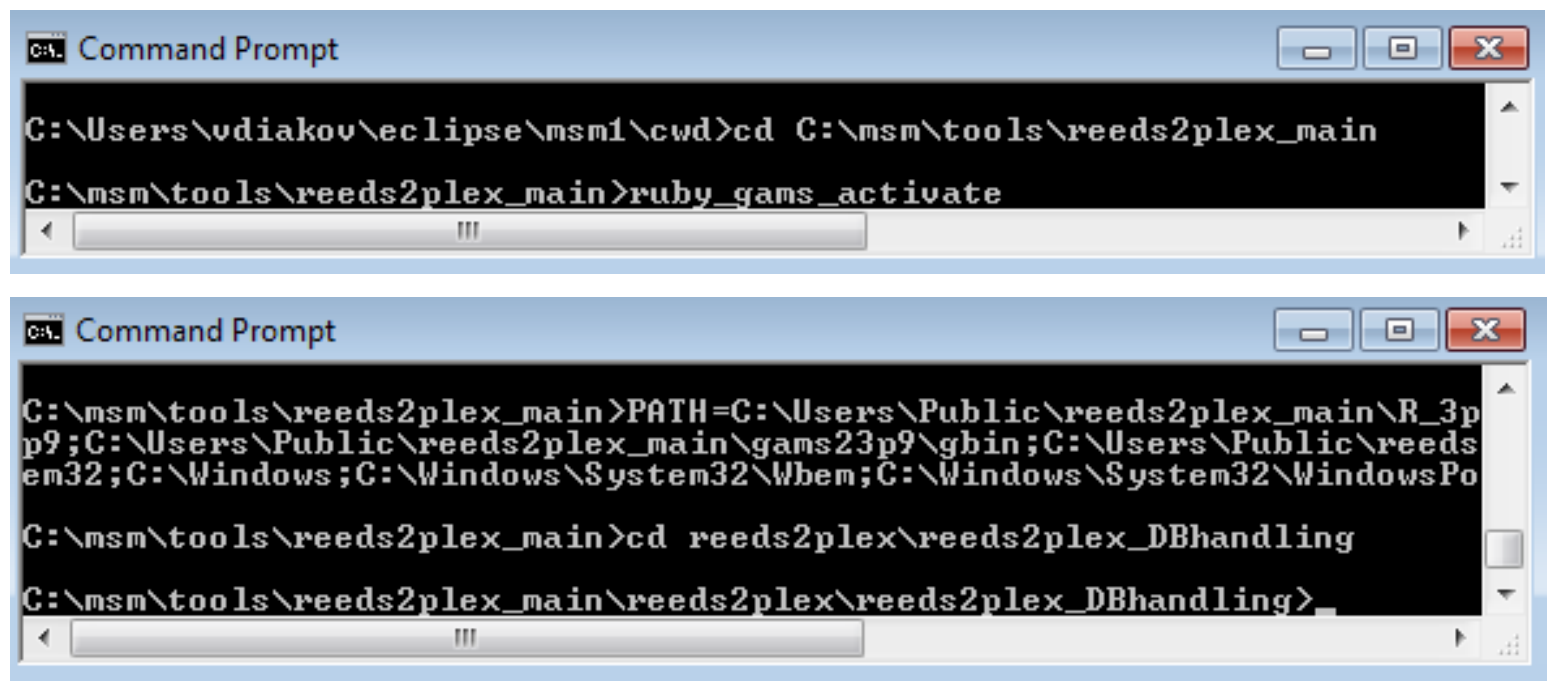

Figure A4. Example command window before (top) and after (bottom) executing the ruby_gams_activate command. 
iv) In the command window, run the reeds_to_plex batch file. ${ }^{14}$ It takes about 20 min to run. During that time, the Linking Tool will translate ReEDS outputs into following PLEXOS inputs: ${ }^{15}$

a. PLEXOS input database; the Linking Tool will place it in the directory reeds2plex|reeds2plex_DBhandling|result_plex_db under the name reeds_plex.xml. The user needs to move it to the reeds2plex_main $\mid W E C C$ directory and rename as appropriate. The PLEXOS database will work properly only when placed in the WECC directory.

b. Load profiles (i.e. load time-series), re-scaled according to ReEDS scenario, in the WECC $\mid$ ScaledLoad directory. These files do not need to be moved to a different location. The PLEXOS input database reeds_plex will use them in this directory ${ }^{16}$ (assuming the user has a PLEXOS license for the machine where the Linking Tool is located). The Linking Tool will normally not scale generators in non-U.S. WECC regions.

c. PV generation profiles, re-scaled, in WECC $\mid$ FixedDispatch $\mid R P M \_s o l a r$. As in item (b) above, it is not necessary to move these profiles.

d. Wind generation profiles, re-aggregated from the selected WWSIS database, in WECC $\mid$ FixedDispatch $\mid R P M \_$wind.

v) For transmission-constrained PLEXOS scenarios, it may be needed to use the transmission expansion algorithm. The procedure described here deals with interface limitations (interfaceLimitsMin and interfaceLimitsMax, csv files in the WECC directory ${ }^{17}$ ) for "zonal" PLEXOS runs and does not rely on ReEDS transmission expansion. For that, an iterative procedure (described in the WWSIS-2 study) is employed by running the script ruby_run_plex_B2.rb from the WECC directory (... $\mid$ WECC $>$ ruby .. |reeds 2 plex|reeds 2 plex_DBhandling $\left.\mid r u b y \_r u n \_p l e x \_B 2 . r b\right)$. The script contains explicit references to the PLEXOS input database and to the "model"18 from that database, and these references will need to be updated. Note that the script will run PLEXOS repeatedly (within an iterative procedure) and this is time consuming. It is recommended to make following changes (easily done via PLEXOS user interface) that decrease the computation time by a factor of $>10$ with little effect on inter-regional transmission limitations:

a. Remove reserve requirements from the PLEXOS "model."

\footnotetext{
${ }^{14}$ The package also allows linking RPM (Trieu et al. 2013) to PLEXOS. In this case, step (i) uses the directory reeds2plex|reeds2plex_DBhandling $|n g s|$, and the command for step (iv) is 'ruby rpm_thermal.rb'

${ }^{15}$ The batch command reeds_to_plex generates log-files (extension 'txt'). If the log files already exist, the new ones will be appended to them; it might be convenient to delete the old log files before running the batch file. In the batch file, the names of the log-files (three of them) follow the ">>" sign.

${ }^{16}$ If needed, the directory can be renamed; then, all references to that directory from the input PLEXOS database need to be changed as well (using a text editor, or reeds2plex_DBhandling $\backslash$ result_plex_db $\backslash$ replace_text.rb).

${ }^{17}$ To avoid unintended transmission expansion runs "on top of" previous transmission expansion( $\left.\overline{\mathrm{s}}\right)$, the user may check the dates of the interfaceLimits files. A backup set of the original(s) is in the WECClinterfaceLimits_bak directory.

${ }^{18}$ Within PLEXOS, the term "model" means a specific way of running PLEXOS on a given input database. A database usually includes several models, and the "model" needs to be specified to define a PLEXOS simulation.
} 
b. Switch PLEXOS computations from mixed-integer to linear relaxation.

c. The flat files output (i.e. output in csv format) has to be activated. Turn off the output for "period," "month," and "year" as it takes significant amount of time for PLEXOS to save the flat files. The "daily" PLEXOS output has to be activated since it is used by the transmission expansion script.

d. Instead of hourly time intervals, the user can choose calculations with two- or three-hour intervals.

e. The user may choose to shorten the PLEXOS time horizon from 1 year to $1 / 2$ or even shorter for a limited number of iterations, and then continue the transmission expansion with full-year PLEXOS runs.

The five steps (A-E) described briefly above will create a PLEXOS case that corresponds to a specific ReEDS scenario.

\section{A.4 Improving the Linking Tool: Additional Units}

As mentioned in Section 1.3, while executing the Linking Tool, new generating units cannot be added to the existing set of PLEXOS generators. Additional units, however, were added beforehand to improve the quality of the match between the prescribed (ReEDS) and realized (in PLEXOS) regional generation capacity.

Eight units of each type (coal, CC, CT, geothermal) were added in every reserve region (the PLEXOS input database for the Western Interconnect has 10 reserve regions). These generators are referred to as "on-hold" units. The Linking Tool can switch them on (their default state if "off"), scale and assign on-hold generators to buses within their reserve region.

The inter-regional "borrowing" (as, for example, indicated by the arrow on Figure 4) is thus replaced with on-hold generators. No on-hold generators were created for PV, CSP and wind because generation profiles for them are location-specific. 